\title{
CARACTERÍSTICAS DAS POLÍTICAS DE COMPRA E VENDA DE PEQUENAS EMPRESAS DO SUL DE SANTA CATARINA
}

Aline Luiza Brusco Pletsch ${ }^{1}$

Rodney Wernke ${ }^{2}$

Ivone Junges ${ }^{2}$

\footnotetext{
${ }^{1}$ Universidade Comunitária da Região de Chapecó

${ }^{2}$ Universidade do Sul de Santa Catarina (UNISUL)
} 


\section{CARACTERÍSTICAS DAS POLÍTICAS DE COMPRA E VENDA DE PEQUENAS EMPRESAS DO SUL DE SANTA CATARINA}

Resumo: Objetivou identificar as características das políticas de compra e venda das pequenas empresas de microrregião do sul catarinense. Para tanto, foi efetuada sondagem que abrangeu 299 empresas. Os resultados destacaram a preponderância das vendas com prazos inferiores a 90 dias e a preferência por receber dos clientes por depósitos bancários (fábricas) e em dinheiro (comércio). O nível de inadimplência predominante ficou entre $0,1 \%$ e $2,0 \%$ das vendas a prazo e a análise do histórico do cliente foi a medida mais usada na concessão de crédito. Nas compras verificou-se que os prazos de pagamento eram, em sua na maioria, inferiores a 90 dias, mas pouco menos de $42 \%$ das fábricas conseguiam prazo maior. O boleto bancário foi a modalidade de pagamento mais utilizada nas empresas fabris e nas demais. A maioria das participantes não mensura o prazo médio de permanência no estoque, mas naquelas que medem-no este situa-se em 45 dias.

Palavras-chave: Pequenas empresas. Políticas de compra e venda. Survey.

\section{Introdução}

A capacidade das pequenas empresas atuarem de forma competitiva nos respectivos segmentos de mercado está amplamente vinculada à formulação de estratégias de negócios nas quais são levadas em consideração as ações e reações dos concorrentes diretos, assim como a existência e importância de fornecedores, clientes e produtos alternativos que auxiliem quanto às necessidades dos mercados onde estas empresas atuam (LUPOLI JUNIOR, 2016).

Além disso, o ambiente econômico de mercado das pequenas empresas é caracterizado por uma concorrência acirrada, onde as políticas de compra e vendas passam a ter grande importância. Então, para conseguirem se manter competitivas estas necessitam adequar seus procedimentos operacionais a fim de atingir determinados níveis de qualidade, custos competitivos e políticas de precificação que, muitas vezes, são viáveis apenas na realidade das grandes empresas. Porém, os maiores afetados por alterações no ambiente competitivo têm sido as pequenas e médias empresas, que geralmente têm menos recursos à disposição para resistirem a essas mudanças (CARR ̃̃O, 2004; FARIAS FILHO et al., 1999).

Nesse sentido, diversos fatores afetam a realidade competitiva das empresas e têm merecido a atenção de pesquisadores. Entre esses destaca-se o aumento da influência dos compradores para estabelecerem o preço e as formas pelas quais se dispõem a pagar pela aquisição de bens e serviços. Isso acarreta a redução do poder das empresas vendedoras para estabelecer o preço e a forma de recebimento das vendas, passando a ser uma característica presente na maior parte dos segmentos mercadológicos, independentemente do porte das organizações (BERLINER; BRIMSON, 1992; SHANK; GOVINDARJAN, 1997; IUDÍCIBUS, 1998; KAPLAN; COOPER, 1998; ATKINSON et al., 2000).
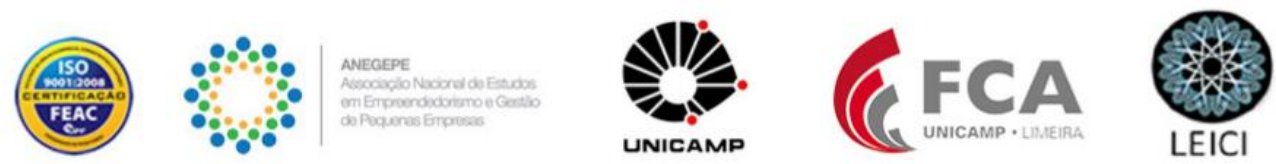
Destarte, a gestão dos prazos de compra e venda deve ser prioridade para os administradores que almejam melhorar o desempenho das finanças da organização que dirigem. Essa relevância provavelmente também ocorre no âmbito da administração financeira das pequenas empresas da microrregião da Amurel, no sul de Santa Catarina, visto que a concorrência mercadológica praticamente obriga a equiparação dos prazos concedidos aos clientes no segmento de atuação. Por outro lado, o reduzido poder de barganha perante fornecedores tende a acarretar para esses empreendimentos de pequeno porte a obrigação de aceitarem os prazos impostos por fornecedores nas compras realizadas a prazo, o que acaba dificultando a competitividade perante empresas maiores, que usufruem de condições de financiamento mais acessíveis ou da concessão de prazos de pagamentos mais extensos.

Contudo, essa suposição não foi devidamente comprovada por estudos científicos anteriores, o que abre uma lacuna que se pretende contribuir para sanar por intermédio desta pesquisa. Assim, se pretende responder à seguinte questão de estudo: quais as características das políticas de compra e venda adotadas pelas pequenas empresas sediadas na microrregião da Amurel? Para tanto, foi estabelecido como objetivo de estudo identificar as características das políticas de aquisição e comercialização das empresas de pequeno porte da microrregião citada.

Estudos com esse foco se justificam por, ao menos, dois aspectos: pela relevância econômica das pequenas empresas e pela necessidade de se conhecer as práticas adotadas pelas micros e pequenas empresas no que concerne às políticas de compra e venda. No campo econômico, diversos estudos salientaram a importância das pequenas empresas para a economia de várias nações, especialmente quanto à geração de empregos e renda (IIDA, 1986; RESNIK, 1991; BATY, 1994; SCHELL, 1995; VAN STEL; CARRE; THURIK, 2005, AUDRETSCH; BECHMANN, 2007).

Por outro lado, também são publicados com frequência pesquisas que evidenciam a existência de aspectos que tolhem a competitividade destas e que podem levar à extinção precoce das mesmas (SEBRAE, 2013; VOGEL; WOOD JR., 2012). Portanto, é coerente cogitar que uma parte dessas dificuldades está atrelada à necessidade de captação de recursos para financiar as operações mercantis, especialmente em relação ao capital de giro requerido para suportar o ciclo financeiro, notadamente quando este envolve o pagamento das compras antes do recebimento das vendas (CARVALHO; ABRAMOVAY, 2004; WERNKE; JUNGES; FRANCISCO, 2016).

Como essa realidade provavelmente está presente na microrregião da Amurel, com esta pesquisa se almeja contribuir com a ampliação dos conhecimentos sobre esse contexto por meio de um diagnóstico acerca do tema na região mencionada. Com isso, se pretende também evidenciar informações úteis para associações comerciais, órgãos governamentais de crédito, profissionais da gestão financeira e pesquisadores das instituições universitárias da região mencionada acerca das políticas de compra e venda adotadas pelas empresas de pequeno porte.

\section{Referencial Teórico}

A atenção às políticas de compra e venda é importante porque a gestão ineficiente do capital de giro foi apontada como o principal motivo para o fechamento de micro e pequenas empresas no Brasil (SEBRAE, 2007). Por isso, é vital que proprietários e gestores aprimorem a gestão financeira de curto prazo, visando garantir longevidade às firmas (CARVALHO, SCHIOZER, 2012).

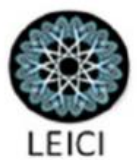


Nessa linha de raciocínio, Assaf Neto (2003) comenta que a administração do capital de giro dedica-se às decisões de compra e venda e também às mais diversas atividades operacionais e financeiras de uma empresa. Nesta perspectiva, a gestão do capital de giro deve ser a garantia de uma correta aplicação das suas políticas de estocagem, de compra de materiais, de produção, de venda de produtos e mercadorias e da adequação dos prazos de recebimento e pagamento.

No âmbito desta pesquisa foram priorizadas as políticas de compra e venda. No caso dos processos de compras, estes possuem grande relevância principalmente quando se considera a tendência mundial de mercado relacionada à terceirização de atividades, onde pode ocorrer um aumento no número de itens comprados por uma empresa. Além disso, a globalização de mercados faz com que as empresas sejam "companhias de classe mundial" comprando e vendendo de todos e para todos os pontos do mundo (SALOMON, 2002). Do mesmo modo, Santos (1997) salienta que na definição da política de vendas se deve considerar que o cenário atual se caracteriza pela alta competitividade e uma constante mudança tecnológica, onde as empresas necessitam interagir de maneira coordenada visando sua continuidade no longo prazo.

Isso é pertinente porque os procedimentos relacionados com as políticas de compra e venda das empresas afetam diretamente o ciclo financeiro destas. Sobre o assunto, Assaf Neto (2003) aduz que o Ciclo Financeiro identifica as necessidades de recursos da empresa que ocorrem desde o momento do pagamento aos fornecedores até o efetivo recebimento das vendas realizadas; enquanto que Padoveze e Benedicto (2004) salientam que o ciclo financeiro se estende do evento "pagamento das compras" até o "recebimento da venda". Na mesma direção, Santos (2001) cita que o Ciclo Financeiro abrange o intervalo de tempo entre os eventos financeiros ocorridos ao longo do ciclo operacional, representado pelo pagamento a fornecedores e pelo recebimento das vendas. Para exemplificar, relata um caso industrial onde a fabricação começa após a compra da matéria-prima e a venda é concretizada somente após a fabricação. Nesse caso, assevera que o ciclo financeiro é calculado com base no prazo de fabricação e nos prazos de pagamento de compras e recebimento das vendas.

Além disso, estudos indicam a existência de relação positiva entre gestão do capital de giro e a rentabilidade da empresa em diferentes países. Deloof (2003) analisou essa relação por meio de uma amostra de 1.009 empresas belgas de grande porte (não-financeiras) no período de 1992-1996. O resultado apresentou uma relação negativa entre rentabilidade e ciclo financeiro; assim, quanto maior a rentabilidade, menor o ciclo financeiro. Concluiu que os gestores podem aumentar a rentabilidade das organizações reduzindo o número de dias dos valores a receber e a rotação dos estoques. As instituições com menor rendimento esperaram mais dias para pagar suas contas em relação àquelas com maior rentabilidade.

Por sua vez, Aquegawa e Souza (2010) objetivaram identificar, a partir dos índices de liquidez e ciclo financeiro, os impactos da crise de 2008 nos diversos setores participantes do ISE. A trajetória apontada pelas retas de tendência dos indicadores no período analisado, quando são relacionadas aos resultados efetivos, mostram uma minimização dos impactos sobre o todo analisado. Os referidos autores atribuem como motivo para tais resultados a avaliação de empresas/setores no momento da constituição da carteira (ISE), que pode ser considerada relativamente estável e equilibrada financeiramente.

Entre os fatores componentes do Ciclo Financeiro, no âmbito das aquisições de insumos o gestor financeiro deve avaliar a adequação do prazo obtido para pagar os fornecedores, pois

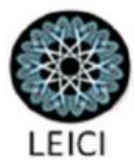


deveria considerar na negociação de prazos com os fornecedores as políticas de comercialização adotadas pela própria empresa. Assim, conforme Lemes Junior et al. (2002), deve-se procurar comprar as matérias-primas (ou mercadorias) em prazos que sejam, pelo menos, iguais aos oferecidos aos clientes. Com isso, se a empresa vende a prazo deve procurar comprar a prazo de forma que seu prazo médio de recebimento seja menor (ou igual) ao prazo médio de pagamento aos fornecedores. Porém, mesmo que essa seja uma situação ideal, tem ocorrência pouco frequente no contexto de pequenas empresas, cujo poder de negociar prazos com fornecedores tende a ser pequeno.

Quanto aos fatores relacionados às vendas, o prazo de recebimento das mesmas merece ser monitorado constantemente. Silva (2005) advoga que o prazo de recebimento pode ser mensurado pelo espaço de tempo médio que as vendas levam para se transformar em disponibilidades de caixa e determina os investimentos necessários em contas a receber. Cita, também, que é comum os gerentes de vendas dilatarem os prazos de recebimento das vendas como estratégia de marketing visando aumentar o faturamento. Mas, se esse procedimento administrativo não tiver suporte financeiro adequado, poderá acarretar o comprometimento da liquidez da empresa. No mesmo sentido, Lemes Junior et al. (2002) asseveram que é interessante que os gestores atentem para o prazo de recebimento, pois comercialmente este é tão importante quanto a concessão do crédito em si, sendo decisivo tanto para quem pleiteia o crédito como para quem está analisando a sua concessão. Pelo aspecto financeiro, tais autores ilustram a relevância do gerenciamento desses prazos argumentando que investir na concessão de crédito representa ter disposição de assumir os custos visando benefício futuro, ou seja, rentabilidade. Portanto, quanto maior o prazo concedido, maior o tempo do investimento e, consequentemente, maiores os custos do investimento.

\section{Metodologia}

Quanto ao desenho metodológico, esta pode ser caracterizada como uma pesquisa quantitativa de descrição. Rauen (2015, p. 157) menciona que esse tipo de estudo é mais conhecido como de "levantamento de dados, de sondagem ou survey e consiste na solicitação de informações a um grupo estatisticamente significativo de pessoas para posterior análise quantitativa, recorrendo-se a técnicas de pesquisa de campo". Nessa direção, Andrade (2002) pugna que os estudos descritivos se preocupam em observar os fatos, registrá-los, analisá-los, classificá-los e interpretá-los, sem a interferência direta do pesquisador no contexto.

Por outro lado, Carvalho e Schiozer (2015, p.215) ressalvam que as pesquisas do tipo survey estão sujeitas a limitações, que podem advir da existência de potenciais vieses de "não respondentes", de "aquiescência", de "straight-line" e de "respostas socialmente desejáveis". Nesse rumo, Gil (2010) destaca como uma das possíveis limitações desse tipo de estudo a ênfase em aspectos perceptivos, visto que levantamentos recolhem dados que se referem às impressões das pessoas acerca de si mesmas. Isto pode gerar distorções, porque há muita divergência entre o que as pessoas fazem (ou sentem) e o que elas dizem a respeito.

No que tange à forma de abordagem quantitativa, Richardson et al. (1999) aduzem que essa modalidade envolve as pesquisas que empregam a quantificação, tanto nas modalidades de coleta de informações, quanto no tratamento dessas por meio de técnicas estatísticas, desde as mais simples (como percentual, média, desvio padrão etc.) até aquelas mais complexas (como coeficientes de correlação, análises de regressão, testes estatísticos etc.).
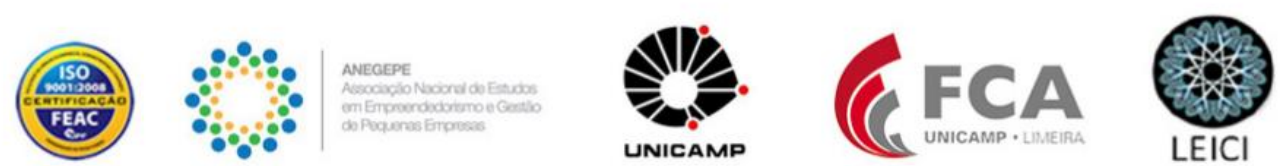
Quanto ao procedimento de coleta de dados, este aconteceu por intermédio da aplicação de questionário específico, nos meses de abril a junho de 2016. Esse questionário inicialmente foi testado em um grupo de cinco possíveis respondentes (que posteriormente não participaram do estudo final) para ajustar as questões incluídas. Referidos questionários foram preenchidos a partir das informações coligidas nas empresas por um grupo de alunos de curso de Administração de universidade sediada na área geográfica abrangida, devidamente treinados para essa atividade.

A amostra final utilizada envolveu 299 (duzentos e noventa e nove) empresas, sendo que desse total, 232 firmas $(77,59 \%)$ atuavam como "comércio /serviços" e outras 67 empresas $(22,41 \%)$ eram indústrias. Nesse rumo, fizeram parte do estudo somente as pequenas empresas da microrregião conhecida por Associação dos Municípios da Região de Laguna (Amurel), localizada no sul de Santa Catarina, cujos gestores concordaram em participar. Portanto, caracteriza-se por amostra de caráter intencional, associada à possibilidade de acesso aos dados desse conjunto de firmas por parte dos pesquisadores. Quanto ao critério utilizado para qualificar como pequena empresa, foi utilizado o de "número de empregados", pois este teria maior possibilidade de ser revelado pelos respondentes do que o critério "faturamento".

É pertinente destacar, também, que a análise dos dados foi realizada por meio de estatística descritiva, onde foi priorizada a participação percentual nos dois grupos de empresas abrangidos.

\section{Apresentação dos Dados e Discussão dos Resultados}

As próximas seções evidenciam os dados coligidos e comentam as informações oriundas das respostas obtidas a partir do questionário aplicado na amostra de empresas abrangidas.

\subsection{Políticas de Vendas}

O primeiro tema abordado no estudo diz respeito aos principais aspectos da política de vendas adotada pelas pequenas firmas participantes da pesquisa. Nessa direção, foram obtidos dados acerca dos prazos de recebimento dos clientes, da influência dos concorrentes nos prazos concedidos à clientela, do índice de inadimplência e dos critérios de concessão de crédito, conforme descrito na sequência.

Inicialmente foi indagado sobre o prazo de recebimento das vendas efetuadas, onde os participantes informaram qual o percentual do faturamento realizado em sete categorias de prazos de concedidos, conforme sintetizado na Tabela 1.

Tabela 1 - Prazos de Recebimento das Vendas

\begin{tabular}{lrrrrrrr}
\hline & $\begin{array}{r}\text { Não } \\
\text { houve }\end{array}$ & $\begin{array}{r}\text { Entre } \\
1 \%-10 \%\end{array}$ & $\begin{array}{r}\text { Entre } \\
11 \%-25 \%\end{array}$ & $\begin{array}{r}\text { Entre } \\
26 \%-50 \%\end{array}$ & $\begin{array}{r}\text { Entre } \\
51 \%-75 \%\end{array}$ & $\begin{array}{r}\text { Entre } \\
76-100 \%\end{array}$ & Total \\
\hline À vista-Total & 20 & 56 & 83 & 62 & 44 & 34 & 299 \\
À vista-Com. & 16 & 28 & 68 & 50 & 39 & 31 & 232 \\
À vista-Ind. & 4 & 28 & 15 & 12 & 5 & 3 & 67 \\
Entre 15-30 dias-Total & 31 & 63 & 77 & 79 & 35 & 14 & 299 \\
Entre 15-30 dias-Com. & 26 & 45 & 55 & 67 & 27 & 12 & 232 \\
Entre 15-30 dias-Ind. & 5 & 18 & 22 & 12 & 8 & 2 & 67 \\
Entre 31-45 dias-Total & 70 & 70 & 60 & 60 & 29 & 10 & 299
\end{tabular}




\begin{tabular}{|c|c|c|c|c|c|c|c|}
\hline Entre 31-45 dias-Com. & 60 & 53 & 46 & 44 & 22 & 7 & 232 \\
\hline Entre 31-45 dias-Ind. & 10 & 17 & 14 & 16 & 7 & 3 & 67 \\
\hline Entre 46-90 dias-Total & 105 & 67 & 50 & 42 & 30 & 5 & 299 \\
\hline Entre 46-90 dias-Com. & 89 & 52 & 42 & 31 & 15 & 3 & 232 \\
\hline Entre 46-90 dias-Ind. & 16 & 15 & 8 & 11 & 15 & 2 & 67 \\
\hline Entre 91-135 dias-Total & 183 & 52 & 27 & 19 & 14 & 4 & 299 \\
\hline Entre 91-135 dias-Com. & 146 & 42 & 20 & 15 & 7 & 2 & 232 \\
\hline Entre 91-135 dias-Ind. & 37 & 10 & 7 & 4 & 7 & 2 & 67 \\
\hline Entre $136-180$ dias-Total & 220 & 44 & 17 & 11 & 6 & 1 & 299 \\
\hline Entre 136-180 dias-Com. & 176 & 32 & 12 & 9 & 3 & - & 232 \\
\hline Entre 136-180 dias-Ind. & 44 & 12 & 5 & 2 & 3 & 1 & 67 \\
\hline Superior 180 dias-Total & 230 & 41 & 11 & 6 & 6 & 5 & 299 \\
\hline Superior 180 dias-Com. & 182 & 30 & 8 & 4 & 8 & - & 232 \\
\hline Superior 180 dias-Ind. & 48 & 11 & 3 & 2 & 2 & 5 & 67 \\
\hline
\end{tabular}

Fonte: dados da pesquisa.

Na Tabela 1 e nas seguintes os dados estão segregados em três categorias: "Comércio" (agrupando 232 pequenas empresas), "Indústria" (que envolve 67 fábricas de pequeno porte) e "Total" (a soma dos dois grupos citados).

As respostas obtidas permitem concluir que os prazos mais extensos foram priorizados por uma parcela menor dos empreendimentos abrangidos no estudo. No caso das empresas comerciais, as vendas faturadas com prazos superiores a 90 dias foram realizadas por menos de $40 \%$ destas e, à medida que o prazo aumentava para além desse período, o percentual caía (menos de $25 \%$ venderam com prazo superior a 136 dias). No âmbito das fábricas a situação era assemelhada, de vez que menos de $45 \%$ destas firmas concederam prazo acima de 90 dias, menos de $35 \%$ faturaram para mais de 136 dias e abaixo de 30\% destas (apenas 48 indústrias) venderam com prazo acima de 180 dias.

Quanto aos prazos inferiores a três meses, foram constatadas divergências entre as políticas adotadas pelas empresas fabris e as utilizadas nas demais. No que tange às vendas à vista, no caso industrial cerca de 41,79\% dos respondentes (28 de 67 empresas) citaram que esta forma de faturamento abrangia entre $1 \%$ e $10 \%$ dessa modalidade de venda, contra apenas $12,07 \%$ das 232 comerciais. Nas varejistas o maior contingente de respostas sobre as vendas à vista se localizou na faixa que envolvia entre $11 \%$ e $25 \%$, com 68 empresas $(29,31 \%$ do total pesquisado).

No que concerne às vendas com prazo de recebimento entre 15 e 30 dias, a parcela mais expressiva do grupo industrial situou-se na opção de resposta "entre $11 \%$ e $25 \%$ ", enquanto que no comércio a alternativa mais apontada (por 28,88\% dos respondentes) foi aquela que dizia abranger "entre $26 \%$ e 50\%". Ainda, no caso da faixa de prazo entre "31 e 45 dias", praticamente a metade $(48,70 \%)$ das empresas comerciais informou que "não houve" $(25,86 \%)$ ou que representava entre $1 \%$ e $10 \%$ do faturamento $(22,84 \%)$. Pelo lado industrial, essas duas faixas englobaram $40,30 \%$ das respostas.

$\mathrm{O}$ segundo ponto inquirido visava conhecer a influência da concorrência na determinação dos prazos de venda ofertados à clientela, cujas respostas estão na Tabela 2. 
Tabela 2 - Impacto dos concorrentes no prazo concedido a clientes

\begin{tabular}{lrrrrrr}
\hline & \multicolumn{2}{c}{ Comércio } & \multicolumn{2}{c}{ Indústria } & \multicolumn{2}{c}{ Total } \\
Itens & Quantidade & $\%$ do total & Quantidade & $\%$ do total & Quantidade & $\%$ do total \\
\hline Irrelevante & 21 & $9,05 \%$ & 7 & $10,45 \%$ & 28 & $9,36 \%$ \\
Mínimo & 51 & $21,98 \%$ & 9 & $13,43 \%$ & 60 & $20,07 \%$ \\
Importante & 83 & $35,78 \%$ & 20 & $29,85 \%$ & 103 & $34,45 \%$ \\
$\begin{array}{l}\text { Muito importante } \\
\text { Extremamente }\end{array}$ & 46 & $19,83 \%$ & 20 & $29,85 \%$ & 66 & $22,07 \%$ \\
$\begin{array}{l}\text { importante } \\
\text { Total }\end{array}$ & & & & & & \\
\hline
\end{tabular}

Fonte: dados da pesquisa.

No grupo de empresas comerciais o impacto dos concorrentes foi considerado "Irrelevante" ou "Mínimo" por 31,03\% dos respondentes, enquanto que no âmbito fabril esse patamar foi de $23,88 \%$. Em razão disso, pode-se concluir que a força dos competidores se faz mais presente no caso industrial, visto que 76,12\% das 67 firmas qualificaram essa influência como "Importante", "Muito importante" ou "Extremamente importante".

Por sua vez, no grupo do comércio esses níveis de importância foram atribuídos por 68,97\% das 232 empresas. Ainda, o percentual médio da relevância atribuída aos concorrentes no conjunto de 299 participantes chegou a $70,57 \%$, contra $29,43 \%$ daqueles que responderam ser irrelevante ou minimamente importante.

A questão seguinte abordou as formas de recebimento adotadas pelas companhias em tela, cuja síntese está representada na Tabela 3.

Tabela 3 - Forma de recebimento das vendas

\begin{tabular}{lrrrrrrr}
\hline & Não & Entre & Entre & Entre & Entre & Entre \\
Itens & houve & $1 \%-10 \%$ & $11 \%-25 \%$ & $26 \%-50 \%$ & $51 \%-75 \%$ & $76-100 \%$ & Total \\
\hline Dinheiro-Total & 37 & 64 & 65 & 56 & 37 & 40 & 299 \\
Dinheiro-Com. & 24 & 37 & 53 & 49 & 33 & 36 & 232 \\
Dinheiro-Ind. & 13 & 27 & 12 & 7 & 4 & 4 & 67 \\
Depósito em c/c-Total & 86 & 97 & 49 & 36 & 15 & 16 & 299 \\
Depósito em c/c-Com. & 78 & 73 & 32 & 26 & 9 & 14 & 232 \\
Depósito em c/c-Ind. & 8 & 24 & 17 & 10 & 6 & 2 & 67 \\
Cheque pré-datado-Total & 82 & 73 & 51 & 53 & 28 & 12 & 299 \\
Cheque pré-datado-Com. & 69 & 58 & 39 & 39 & 21 & 6 & 232 \\
Cheque pré-datado-Ind. & 13 & 15 & 12 & 14 & 7 & 6 & 67 \\
Cartão déb./créd.-Total & 132 & 47 & 35 & 41 & 27 & 17 & 299 \\
Cartão déb./créd.-Com. & 90 & 32 & 30 & 38 & 27 & 15 & 232 \\
Cartão déb./créd.-Ind. & 57 & - & 5 & 3 & - & 2 & 67 \\
Boleto bancário-Total & 153 & 34 & 26 & 25 & 32 & 29 & 299 \\
Boleto bancário-Com. & 138 & 29 & 16 & 11 & 16 & 22 & 232 \\
Boleto bancário-Ind. & 15 & 5 & 10 & 14 & 16 & 7 & 67 \\
Carnê pago na empresa-Total & 231 & 23 & 18 & 12 & 6 & 9 & 299 \\
Carnê pago na empresa-Com. & 176 & 18 & 14 & 12 & 6 & 6 & 232 \\
Carnê pago na empresa-Ind. & 67 & - & - & - & - & 3 & 67 \\
\hline
\end{tabular}

Fonte: dados da pesquisa. 
Do contexto descrito na Tabela 3 optou-se por destacar os seguintes pontos:

1) O recebimento das vendas em "dinheiro" representava entre " $1 \%$ e $10 \%$ " do faturamento para $40,30 \%$ dos respondentes das indústrias, enquanto que $43,96 \%$ dos comerciantes afirmavam que este tipo de recebimento representava entre " $11 \%$ e $25 \%$ " do total faturado e entre " $26 \%$ e $50 \%$ " da receita (respectivamente $22,84 \%$ e $21,12 \%$ das respostas).

2) O depósito em conta corrente abrangia parcela maior das vendas na indústria, visto que $61,19 \%$ das respostas citaram que esta forma de recebimento respondia por parcela entre " $1 \%$ e $10 \%$ " das vendas $(35,82 \%$ das respostas $)$ e $25,37 \%$ dos participantes citaram abranger entre " $11 \%$ e $25 \%$ " do montante faturado. No que concerne às empresas comerciais, pouco mais de um terço $(33,62 \%)$ dos participantes afirmaram não ter ocorrido essa modalidade de quitação e $31,47 \%$ dos respondentes asseveraram que o depósito bancário representava entre " $1 \%$ e $10 \%$ do valor do faturamento do período.

3) O cheque pré-datado não era aceito no pagamento de vendas por cerca $29,74 \%$ das empresas comerciais e, para $25 \%$ destas, tal forma de pagamento possibilitava receber entre " $1 \%$ e $10 \%$ " do faturamento. Entretanto, nas industriais o quadro apurado foi distinto, de vez que somente $19,40 \%$ das respostas deste tipo de empresa informaram que "não houve" essa forma de cobrança.

4) O pagamento dos clientes por "Cartão de débito/crédito" também deslindou outra divergência entre as entidades fabris e comerciais. No caso das indústrias, 57 das 67 empresas (mais de $85 \%$ ) assinalaram a opção de que não houve esse tipo recebimento. Porém, no comércio esse percentual foi de apenas 38,79\% (90 de 232 respostas).

5) Boleto bancário: $59,48 \%$ das lojas pesquisadas não utilizaram a cobrança bancária, enquanto nas indústrias esse percentual chegou somente a $22,39 \%$.

6) Carnê pago na empresa: em sua totalidade, as indústrias pesquisadas alegaram que não utilizam esse tipo de cobrança, enquanto que $75,86 \%$ das lojas também afirmaram não fazer uso desta modalidade.

$\mathrm{O}$ quarto aspecto pesquisado relacionado às vendas versava sobre os percentuais de inadimplência suportados pelas empresas nos últimos doze meses. Nesse rumo, a Tabela 4 expõe o cenário apurado a partir do questionário aplicado.

Tabela 4 - Inadimplência nos últimos 12 meses

\begin{tabular}{lrrrrrr}
\hline & \multicolumn{2}{c}{ Comércio } & \multicolumn{2}{c}{ Indústria } & \multicolumn{2}{c}{ Total } \\
& Quantid. & $\%$ do total & Quantid. & $\%$ do total & Quantid. & $\%$ do total \\
\hline Não houve inadimplência & 43 & $18,53 \%$ & 10 & $14,93 \%$ & 53 & $17,73 \%$ \\
Entre 0,1\% e 2,0\% das vendas a prazo & 67 & $28,88 \%$ & 17 & $25,37 \%$ & 84 & $28,09 \%$ \\
Entre 2,1\% e 4,0\% das vendas a prazo & 51 & $21,98 \%$ & 13 & $19,40 \%$ & 64 & $21,40 \%$ \\
Entre 4,1\% e 6,0\% das vendas a prazo & 42 & $18,10 \%$ & 13 & $19,40 \%$ & 55 & $18,39 \%$ \\
Entre 6,1\% e 8,0\% das vendas a prazo & 19 & $8,19 \%$ & 8 & $11,94 \%$ & 27 & $9,03 \%$ \\
Mais que 8,0\% das vendas a prazo & 10 & $4,31 \%$ & 6 & $8,96 \%$ & 16 & $5,35 \%$ \\
Total & 232 & $100,00 \%$ & 67 & $100,00 \%$ & 299 & $100,00 \%$ \\
\hline
\end{tabular}

Fonte: dados da pesquisa. 
Na média, aproximadamente $17,7 \%$ das firmas participantes alegaram que não houve inadimplência relativa às vendas faturadas. Em sentido oposto, no outro contingente de empresas a concentração das respostas mostrou que o nível de inadimplência entre $0,1 \%$ e 6,0\% das vendas a prazo era o de maior ocorrência, afetando mais de $2 / 3$ das empresas $(67,89 \%)$.

Contudo, ao analisar os dados de forma mais detalhada percebeu-se que a situação é mais preocupante no caso do "Comércio", se comparado com a "Indústria". Nas empresas comerciais, aproximadamente $69 \%$ dos respondentes afirmaram que ocorre inadimplência entre os patamares citados, mas com concentração maior na faixa inicial (de " 0,1 " até " $2,0 \%$ "), visto que 67 empresas $(28,88 \%$ das 232 comerciais) estavam nesse estrato. Ainda, 51 firmas $(21,98 \%)$ salientaram ter índice entre " $2,1 \%$ " e " $4,0 \%$ " e 42 empresas $(18,10 \%)$ informaram ter inadimplência na faixa entre " $4,1 \%$ " e " $6,0 \%$ ". No âmbito fabril os números a respeito foram um pouco menores, pois a inadimplência entre " $0,1 \%$ " e " $6,0 \%$ " foi relatada por $64,18 \%$ das 67 indústrias abrangidas, com destaque também para a linha referente à inadimplência entre " $0,1 \%$ " e " $2,0 \%$ ", visto que pouco mais de $1 / 4$ destas $(25,37 \%)$ assinalou a resposta correspondente a essa faixa.

O último foco priorizado da política de vendas almejou identificar os critérios de concessão de crédito mais utilizados pelas empresas em lume, cujas respostas coligidas indicaram que a utilização do histórico do cliente foi o procedimento de análise de crédito mais presente nas respostas coletadas. A respeito disso, mais de $85 \%$ das indústrias informaram utilizá-lo "na maioria das vezes" (31,34\%) ou "sempre" (53,73\%), enquanto que apenas $14,93 \%$ destas raramente usam ou nunca fazem uso deste instrumento. Ainda, foi apurado que nas empresas comerciais a análise do histórico da clientela não era empregado ou era "raramente" utilizado por $41,38 \%$ dos participantes. Por outro lado, 25,86\% alegaram fazer uso na maioria das vezes e $32,76 \%$ citaram que sempre utilizam-no.

Quanto à consulta a entidades como SPC (Serviço de Proteção ao Crédito), Serasa e afins foi averiguado que pouco mais da metade das firmas comerciais pesquisadas não utilizavam esses serviços $(40,09 \%)$ ou raramente faziam isso $(11,64 \%)$. No lado oposto, 48,28\% das lojas mencionavam utilizar frequentemente $(11,21 \%)$ ou sempre $(37,07 \%)$. Em relação ao contexto industrial, apurou-se realidade distinta, pois mais de $2 / 3$ das fábricas aduziram utilizar sempre $(50,75 \%)$ ou na maioria das vezes $(13,43 \%)$ esse critério para conceder crédito, ao passo que $23,88 \%$ não utilizavam esse procedimento.

A obtenção de informações de crédito junto a outros credores dos clientes estava menos presente nas companhias não fabris, pois $63,36 \%$ destas relataram não utilizar $(42,67 \%)$ ou raramente $(20,69 \%)$. Pelo lado industrial restou evidente que pouco mais da metade $(53,73 \%)$ dos participantes alegaram usar na maioria das vezes ou sempre.

Também foi indagado sobre o uso do limite de crédito por cliente, onde também foram percebidos resultados divergentes entre os dois grupos de empresas. Ou seja, o uso desse critério era mais intenso fábricas, de vez que 56,72\% destas utilizavam-no com frequência $(32,84 \%)$ ou sempre $(23,88 \%)$. Porém, no comércio foi identificado que $41,81 \%$ não utilizavam tal parâmetro e $21,98 \%$ raramente faziam uso dele. Assim, apenas pouco mais de um terço dessas firmas concediam crédito considerando o referido limite.

Na mesma questão foram cogitadas as possibilidades inerentes à exigência de avalistas, obrigatoriedade de uma parcela de "entrada" no ato da venda e emprego de índices de liquidez obtidos a partir do balanço patrimonial na concessão de crédito à clientela. Entretanto, estes três

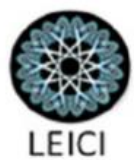


foram os procedimentos menos utilizados. Destarte, mais de $91 \%$ das lojas e indústrias afirmaram não fazer uso (ou raramente usar) da obrigatoriedade de o cliente apresentar avalista/fiador para realizar a aquisição financiada. Além disso, 62,93\% das empresas comerciais não exigia parcela de entrada $(39,66 \%)$ ou raramente exigia $(23,28 \%)$ e $65,67 \%$ das fabris também procediam assim. Por último, quanto aos índices de liquidez o quadro visualizado foi de que nenhuma das 299 entidades pesquisadas fazia uso desses parâmetros contábeis por ocasião da análise de crédito dos clientes. É pertinente salientar que esse resultado unânime pode ser considerado normal ou esperado, tanto no caso industrial quanto comercial, pelo pequeno porte das empresas componentes da amostra pesquisada.

\subsection{Políticas de Compras e Estocagem}

As questões que finalizaram o questionário utilizado versavam sobre as peculiaridades ligadas às políticas de compras e estocagem adotadas pelas empresas abrangidas. Para tanto, foram investigados os prazos de pagamento obtidos de fornecedores, os procedimentos utilizados para quitar as aquisições efetuadas e os prazos de estocagem das compras realizadas.

Inicialmente foi pesquisado sobre os prazos de pagamento das compras obtidos nos últimos doze meses, onde as respostas coletadas trouxeram o cenário comentado a seguir.

No âmbito comercial as compras realizadas com prazos médios superiores a 90 dias foram efetuadas por menos de $22 \%$ das empresas pesquisadas, enquanto que à medida que o prazo aumentava para além desse período o percentual caía (menos de $17 \%$ compraram com a possibilidade de pagamento por prazo superior a 136 dias). No caso fabril a situação foi um pouco diferente, de vez que menos de $42 \%$ destes empreendimentos conseguiram prazo de pagamento de fornecedores acima de 90 dias, enquanto que menos de $20 \%$ compraram para pagar com mais de 136 dias de prazo. Além disso, abaixo de 18\% destas firmas fizeram aquisições com prazo de quitação acima de 180 dias (somente 12 indústrias).

Quanto aos prazos inferiores a três meses, foram constatadas divergências entre as condições de pagamento obtidas pelas empresas industriais e as conseguidas pelas demais. Em termos das compras à vista, nas indústrias abrangidas cerca de $38,81 \%$ dos respondentes $(26$ de 67 empresas) informaram que esta forma de faturamento abrangia entre $1 \%$ e $10 \%$ das compras, contra apenas $29,31 \%$ das 232 varejistas. No comércio, o segundo maior contingente de respostas sobre as compras à vista foi encontrado na faixa que envolvia entre $11 \%$ e $25 \%$ das aquisições, com 50 empresas (21,55\% do total).

No que concerne às compras com prazo de recebimento entre 15 e 30 dias, o grupo com maior número de empresas industriais situou-se na opção de resposta "entre $11 \%$ e $25 \%$ ". Por seu turno, no comércio a alternativa com mais respostas (informada por $27,59 \%$ dos participantes) foi aquela que dizia abranger "entre $26 \%$ e $50 \%$ ". Ainda, no caso da faixa de prazo entre "31 e 45 dias", se constatou que $23,71 \%$ das empresas comerciais relataram que "não houve" ou que representava entre $11 \%$ e $25 \%$ das aquisições de mercadorias $(22,84 \%)$. No contexto industrial essas duas faixas englobaram um total de $44,78 \%$ das respostas.

O passo seguinte do estudo foi na direção de investigar o meio utilizado para efetuar o pagamento das compras junto aos fornecedores de insumos ou mercadorias. Nesse caso, foi apurado que:

a) A quitação das compras com "dinheiro" não foi utilizada por cerca de $24,57 \%$ das empresas comerciais e em $29,85 \%$ das industriais.

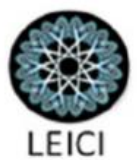


b) Depositar na conta corrente do credor é uma opção preterida por 38,36\% das lojas (89 empresas) e desdenhada por $19(28,36 \%)$ das fábricas abrangidas no estudo.

c) A utilização de cheques pré-datados mostrou diferença acentuada nos percentuais relacionados com a não utilização destes para pagar credores: enquanto 41,38\% dos lojistas asseguraram que não recorreram a essa modalidade de pagamento, somente 22,39\% dos fabricantes informaram que não houve pagamentos dessa forma.

d) Pagamento por intermédio de cartão de débito/crédito foi o segundo instrumento menos utilizado das seis possibilidades apresentadas no questionário (perdendo somente para a compra em consignação). Nesse sentido, 50,43\% das lojas e $65,67 \%$ das fábricas alegaram que não empregaram esta forma de pagamento a fornecedores.

e) Os boletos bancários foram o meio de pagamento mais priorizado no âmbito das entidades participantes do estudo, de vez que apenas $23,28 \%$ das empresas comerciais disseram que não fizeram uso do mesmo e somente 7,46\% das 67 indústrias não faziam pagamentos por intermédio de boletos.

f) Compra em consignação foi o procedimento menos utilizado, visto que apenas oito $(3,45 \%)$ das não fabris e uma indústria $(1,49 \%)$ informaram usar essa modalidade em até $10 \%$ de suas compras.

$\mathrm{Na}$ parte final da pesquisa foi inquirido sobre a estimativa dos prazos médios de estocagem nos dois grupos de empresas participantes, cuja realidade possibilita dessumir que $41,81 \%$ das empresas comerciais não calculavam o prazo médio de estocagem das mercadorias adquiridas, enquanto que quase a metade desse percentual $(23,88 \%)$ é o contingente das indústrias que também não se preocupam com esse indicador relevante para a gestão financeira. Portanto, na média, cerca de 37,79\% das 299 pequenas empresas asseveraram que não calculavam o referido prazo.

No que concerne àquelas que monitoram o período de estocagem, constatou-se uma concentração maior nas faixas de prazos que englobam até 45 dias de estoques. No caso do "Comércio", 43,53\% das firmas deste grupo mantinham estoques por "Até 15 dias" $(9,05 \%)$, "Entre 16 e 30 dias" (13,36\%) e "Entre 31 e 45 dias" (21,12\%). Entretanto, a situação nas fábricas era um pouco diferente, visto que $61,19 \%$ mantinham estoques por até 45 dias, com concentração maior de empresas na faixa "Entre 16 e 30 dias" (26,87\%) e "Até 15 dias" $(22,39 \%)$. Desse modo, concluiu-se que as indústrias têm maior preocupação com a gestão dos prazos de estoques que as firmas comerciais.

\subsection{Discussão dos Resultados}

As seções precedentes deste estudo apresentaram as principais características das políticas de compra e venda de um conjunto de pequenas empresas sediadas na microrregião da AMUREL, cujos principais achados são comentados a seguir.

Inicialmente os resultados mostraram que as empresas de pequeno porte evitam a concessão de prazos longos para recebimento das vendas. Nessa direção, constatou-se que as empresas comerciais realizaram menos da metade de suas vendas com prazo superior a 90 dias, enquanto que situação semelhante também foi verificada com as fábricas, onde apenas $45 \%$ destas concederam prazo superior a 90 dias para clientes. Essa característica de evitar prazos mais extensos, mesmo limitando vendas, tende a ser benéfica do ponto de vista financeiro.

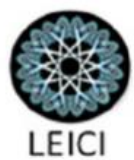


Acerca disso, Martins (1999) registra que um aumento no prazo de recebimento pode provocar uma redução da capacidade financeira, mesmo que isso não comprometa de imediato a rentabilidade. Salienta, também, que é mais fácil para uma empresa realizar alterações em seu fluxo de caixa do que melhorar a lucratividade de suas vendas.

No que concerne à influência da concorrência para determinação dos prazos de vendas concedidos aos clientes, inferiu-se que a maioria das empresas $(70,57 \%)$ atribuiu grande importância para este quesito. O referido resultado contraria as evidências apontadas por Neckel, Andrighi e Hoffmann (2009), que identificaram ser baixa a influência dos concorrentes nas tomadas de decisão dos gestores no contexto deste porte de empresas.

Quanto às principais formas de recebimento das vendas empregadas pelas participantes do estudo, restou evidenciado que o recebimento em dinheiro ainda é significativo para a indústria e para o comércio, representando $22,84 \%$ e $21,12 \%$ respectivamente. Provavelmente em virtude do porte destas firmas, onde costuma prevalecer um grau de informalidade maior, a existência desses percentuais de recebimentos em espécie pode ser considerada normal.

Por outro lado, o depósito em conta bancária foi adotado para recebimento da maior parte das vendas nas indústrias abrangidas no estudo, enquanto que nas comerciais esta forma de cobrança não se mostrou muito representativa. A utilização de cheques pré-datados para liquidar compras dos clientes não era aceita por uma parcela expressiva das companhias comerciais e industriais. No que tange aos recebimentos por cartão de crédito/débito, foram identificadas diferenças entre as empresas fabris e comerciais, sendo que nas empresas fabris a quantidade de vendas cobradas por meio de cartão de crédito/débito foi inferior ao que ocorreu com as empresas comerciais. O recebimento por boleto bancário representou cerca de um terço dos recebimentos na indústria e no comércio tal meio de cobrança representou mais da metade dos recebimentos. Ainda, os carnês para pagamento na empresa não foram utilizados pela maioria das não-fabris e pela totalidade das indústrias investigadas.

Em relação à inadimplência suportada pelas empresas nos últimos 12 meses, foi constatado que apenas 17,7\% das empresas estudadas relataram não possuir inadimplência no período. Com isso, constata-se que a maioria das firmas abrangidas tem problemas relacionados com o não pagamento por parte da clientela.

Quanto aos dados encontrados sobre os critérios de concessão de crédito utilizados pelas empresas, o histórico do cliente foi o critério mais utilizado, sendo feita essa análise por mais de $85 \%$ das indústrias e $58,62 \%$ das empresas comerciais. Além disso, quando indagados acerca da consulta a entidades como SPC, Serasa e outras, foi diagnosticado que mais da metade das empresas comerciais utilizam esses recursos, ao passo que $2 / 3$ das indústrias afirmam utilizarse sempre ou na maioria das vezes. A obtenção de informações creditícias com outros credores dos clientes foi constatada em apenas $36,64 \%$ das empresas comerciais, sendo que no âmbito das fabris 53,73\% fazem uso dessa possibilidade. Sobre o uso do limite de crédito por cliente, percebeu-se que esta medida foi mais utilizada pelas empresas fabris, sendo que nas empresas comerciais apenas pouco mais de um terço destas concediam crédito a seus clientes mediante a estipulação de limite de compras. Outros critérios de concessão de crédito foram analisados (avalista, exigência de entrada na compra e emprego de índices de liquidez), mas mostram-se pouco relevantes para as empresas estudadas, o que ocorre provavelmente em função do porte destas.

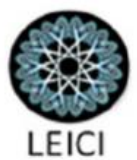


Pelo prisma das compras, também foram estudados determinados aspectos relacionados com as políticas de aquisição e de estocagem. A respeito dos prazos para pagamentos das compras nos últimos 12 meses foi apurado que nas empresas comerciais as compras foram efetuadas, em sua maioria, com prazos inferiores a 90 dias. No caso das entidades fabris a utilização de prazo maior foi mais significativa, pois pouco menos de $42 \%$ destas conseguiram obter prazo de pagamento superior a 90 dias. Além disso, as compras à vista representaram até $10 \%$ do total das compras nos dois grupos de empresas abrangidos. Contudo, essa forma de aquisição não foi adotada por cerca de $25 \%$ das firmas pesquisadas. No caso das compras com prazo de pagamento entre 15 e 30 dias, esta modalidade foi mais frequente no âmbito das indústrias.

$\mathrm{O}$ outro aspecto investigado em relação às compras referiu-se às modalidades de pagamento das compras priorizadas. Nesse sentido, os boletos bancários foram o procedimento preferido para quitação perante fornecedores, enquanto que o depósito em conta corrente foi utilizado por mais de um terço dos respondentes e os cheques pré-datados estavam presentes em grande parte das negociações dos comerciantes e das empresas industriais. Quanto aos instrumentos de quitação das compras menos utilizados, constatou-se que estes foram o cartão de crédito/débito e as aquisições em consignação.

Por último foram verificados os prazos médios de estocagem, o que permitiu assumir que $41,81 \%$ das empresas do comércio não mensuram os prazos médios de estocagem e que $23,88 \%$ das indústrias também procedem assim. Contudo, apurou-se que entre aquelas empresas que medem (ou estimam) o prazo de permanência em estoque, este é menor no caso das empresas fabris, pois as respostas demonstram que estas possuem nível de estoque mais concentrado na faixa entre 16 e 30 dias. Entretanto, no caso das firmas comerciais foi apurado que o prazo de estoques se concentrou entre 31 e 45 dias. Com isso, dessume-se que as indústrias demonstraram preocupação maior com o gerenciamento dos prazos de estoques.

\section{Conclusão}

O presente estudo buscou resposta para questão acerca das características das políticas de compra e venda adotadas pelas pequenas empresas sediadas na microrregião da Amurel. Para tanto, objetivou identificar as peculiaridades das políticas de aquisição e comercialização nas empresas de pequeno porte da microrregião mencionada. Em virtude do exposto nas seções precedentes, entende-se que o objetivo foi alcançado e a pergunta que orienta a pesquisa foi respondida adequadamente.

Quanto aos achados oriundos mais relevantes, cabe destacar alguns pontos. O primeiro aspecto diz respeito à constatação de que as empresas pesquisadas não estão dispostas a conceder prazos extensos para recebimento das vendas feitas para seus clientes, visto que praticam prazos médios inferiores a 90 dias. Provavelmente essa política de concessão de prazos reduzidos está atrelada à influência exercida pelos concorrentes, que também praticam prazos assemelhados. Quanto às formas de recebimento dos clientes foi apurado que o meio mais utilizado nas empresas fabris foi o depósito em conta corrente, enquanto que nas firmas comerciais foi o pagamento em dinheiro. Acerca do nível de inadimplência dos últimos 12 meses dessumiu-se que há maior incidência no estrato entre $0,1 \%$ e $2,0 \%$ das vendas a prazo, tanto para empresas do comércio como para a indústria. Em termos procedimentos para
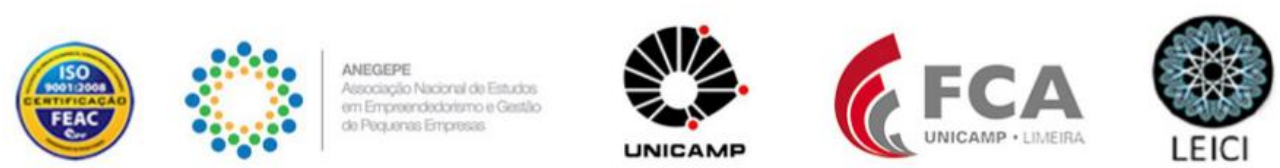
conceder crédito, a utilização de consulta ao histórico do cliente foi a ação que preponderou, de vez que está presente na maioria das vendas efetuadas pelas pequenas empresas abrangidas.

Ainda, no âmbito das políticas atreladas às compras verificou-se que a maior parte das aquisições são pagas em prazo de até 90 dias, enquanto que a principal modalidade de pagamento utilizada era o boleto bancário, tanto para as empresas fabris como para as firmas comerciais. No que concerne aos estoques, a maioria das empresas participantes não mensura o tempo de permanência dos insumos ou das mercadorias em estoque. Contudo, entre aquelas que possuem tal controle o prazo médio situa-se em torno de 45 dias.

Destarte, a principal contribuição do estudo consiste em evidenciar as peculiaridades das políticas relacionadas às compras e vendas adotadas pelas entidades de pequeno porte abrangidas. Com isso, entidades de apoio a esses empreendimentos, associações empresariais, universidades regionais e prestadores de serviços de consultoria financeira passam a ter uma visão mais nítida a respeito das políticas adotadas por esses empreendimentos, o que faculta a definição de prioridades em termos de treinamentos e serviços a ofertar no sentido de fortalecer a gestão financeira dessas pequenas firmas.

Quanto às limitações associáveis ao estudo, é pertinente ressaltar alguns aspectos. O primeiro diz respeito ao fato de que as conclusões estão circunscritas ao contingente de 299 empresas de pequeno porte abrangidas. Desse modo, não cabe generalizar a respeito das conclusões advindas desta pesquisa, especialmente se consideradas outras regiões do estado ou do país, bem como outros portes de empresas. A segunda restrição a considerar diz respeito ao fato de que se assumiu que as respostas fornecidas pelos participantes expressam fielmente a realidade empresarial enfocada, mas não se exigiu dos respondentes uma comprovação fática a respeito. Além disso, uma das particularidades inerentes às pesquisas de levantamento relaciona-se com o fato de que podem ocorrer alguns vieses, por parte dos respondentes, acerca das informações colhidas (como destacado na seção 3, anteriormente), o que pode distorcer o quadro apurado no estudo.

No que tange às recomendações para estudos futuros, sugere-se a análise das políticas de compra e venda de empresas de outros segmentos (ou de outras regiões brasileiras) com o fito de comparar com os resultados ora divulgados. Com isso, conhecer-se-á se as características identificadas neste estrato de empresas se assemelham ou divergem dos demais contextos empresariais.

\section{Referências}

ANDRADE, M. Técnicas de pesquisa: planejamento e execução de pesquisas, amostragens e técnicas de pesquisa, elaboração, análise e interpretação de dados. São Paulo: Atlas, 2002.

AQUEGAWA, H. P.; SOUZA, E. S. A Sustentabilidade financeira a partir dos índices de liquidez e ciclo financeiro: uma análise setorial do portfólio ISE frente a crise de 2010. In: CONGRESSO USP, 10., 2010, São Paulo. Anais... São Paulo: CONGRESSO USP, 2010. CDROM.

ARAÚJO, V. S.; MACHADO, M. A. V. Gestão do capital de giro de pequenas empresas. Journal of Administrative Sciences, v. 13, n. 1, p. 48-61, 2007.

ASSAF NETO, A. Finanças corporativas e valor. 3 ed. São Paulo: Atlas, 2003.

ATKINSON, A. A.; KAPLAN, R. S.; YOUNG, S.; BANKER, R. Contabilidade gerencial. São Paulo: Atlas, 2000.

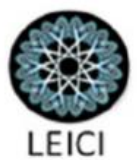


AUDRETSCH, D. B.; BECKMANN, I. A. M. From small business to entrepreneurship policy. In: AUDRETSCH, D. B (Org). Handbook of research on entrepreneurship policy. Massachusetts: Handbook, 2007. p. 36-53.

BATY, G. B. Pequenas e médias empresas dos anos 90: guia do consultor e do empreendedor. São Paulo: Makron Books, 1994.

BERLINER, C.; BRIMSON, J. A. Gerenciamento de custos em indústrias avançadas: base conceitual CAM-I. São Paulo: T.A. Queiroz, 1992.

CARRÃ̃, A. M. R. Cooperação entre empresas de pequeno porte. Revista de Administração da USP, v. 39, n. 2, p. 185-186, 2004.

CARVALHO, C. E.; ABRAMOVAY, R. Diagnóstico da oferta e da demanda de serviços financeiros. In: CARVALHO, C. E. (Org.). O sistema financeiro e as micro e pequenas empresas: diagnósticos e perspectivas. Brasília: Sebrae, 2004. p. 14-45.

CARVALHO, C. J.; SCHIOZER, R. F. Gestão de capital de giro: um estudo comparativo entre práticas de empresas brasileiras e britânicas. RAC-Revista de Administração Contemporânea, v. 16, n. 4, p. 518-543, 2012.

CARVALHO, C. J.; SCHIOZER, R. F. Determinants of Supply and Demand for Trade Credit by Micro, Small and Medium-Sized Enterprises. Revista Contabilidade \& Finanças, v. 26, n. 68, p. 208-222, 2015.

DELOOF, M. Does working capital management affect profitability of Belgian firms. Journal of Business Finance \& Accounting, v. 30, n. 1, p. 573-587, 2003.

FARIAS FILHO, J. R.; CASTANHA, A. L. B.; PORTO, C. B. Arquiteturas em redes: um novo paradigma competitivo para as micro, pequenas e médias empresas. In: ENCONTRO DA ASSOCIAÇÃO NACIONAL DE PROGRAMAS DE PÓS-GRADUAÇÃO EM ADMINISTRAÇÃO, 23, 1999, Foz do Iguaçu. Anais... Foz do Iguaçu: Anpad, 1999.

GIL, A. C. Métodos e técnicas de pesquisa social. 6 ed. São Paulo: Atlas, 2010.

IIDA, I. Pequena e média empresa no Japão. São Paulo: Brasiliense, 1986.

IUDÍCIBUS, S. Contabilidade gerencial. 6. ed. São Paulo: Atlas, 1998.

KAPLAN, R. S.; COOPER, R. Custo e desempenho: administre seus custos para ser mais competitivo. São Paulo: Futura, 1998.

LEMES JÚNIOR, A. B.; RIGO, C. M.; CHEROBIM, A. P. M. S. Administração financeira: princípios, fundamentos e práticas brasileiras. Rio de Janeiro: Campus, 2002.

LUPOLI JUNIOR, J. G. A abordagem estratégica adaptada por uma pequena empresa comercial: um estudo de caso. Revista da FAE, v. 15, n. 2, p. 24-41, 2016.

MARTINS, E. Contabilidade versus fluxo de caixa. Cadernos de Estudos. v. 1, n.1, p. 1-10, 1999.

MONROE, Kent B. Política de precios: para hacer más rentables las decisiones. Madrid: McGraw-Hill, 1992.

NECKEL, A. R.; ANDRIGHI, F. F.; HOFFMANN, V. E. Os stakeholders e sua influência em uma rede de empresa na destinação turística de Urubici/SC. Revista de Negócios, v. 13, n. 4, p. 89-102, 2009.

PADOVEZE, C.; BENEDICTO, G. de. Análise das demonstrações contábeis. São Paulo: Thomson, 2004.

RAUEN, F. Roteiros de iniciação científica: os primeiros passos da pesquisa científica desde a concepção até a produção e a apresentação. Palhoça: Editora Unisul, 2015. 
RESNIK, J. From" Cases" to" Litigation". Law and Contemporary Problems, v. 54, n. 3, p. 5-68, 1991.

RICHARDSON, M. Fundamentos da metodologia científica. São Paulo: Atlas, 1999.

SALOMON, V. A. P. Auxílio à decisão para a adoção de políticas de compras. Produto \& Produção, v. 6, n. 1, p. 1-8, 2002.

SANTOS, E. O. Administração financeira da pequena e média empresa. São Paulo: Atlas, 2001.

SANTOS, R. V. dos. Planejamento do preço de venda. Caderno de estudos, v.1, n. 15, p. 0118, 1997.

SANTOS, R. V. Aplicação do custo de oportunidade às decisões de preço de venda sob o enfoque do custeio direto. In: CONGRESSO BRASILEIRO DE CUSTOS-ABC, 2., 1995. Campinas - SP. Anais... Campinas: CBC, 1995.

SCHELL, J. Guia para gerenciar pequenas empresas: como fazer a transição para uma gestão empreendedora. Rio de Janeiro: Campus, 1995.

SEBRAE - SERVIÇO BRASILEIRO DE APOIO ÀS MICRO E PEQUENAS EMPRESAS. Boletim Estatístico de Micro e Pequenas Empresas - Observatório: 10 semestre de 2005. Brasília: Sebrae, 2005.

SEBRAE - SERVIÇO BRASILEIRO DE APOIO ÀS MICRO E PEQUENAS EMPRESAS. Fatores condicionantes e taxas de sobrevivência e mortalidade das micro e pequenas empresas no Brasil. 2007. Disponível em: 〈http://www.sebrae.com.br>. Acesso em 23 de maio de 2017.

SEBRAE - SERVIÇO BRASILEIRO DE APOIO ÀS MICRO E PEQUENAS EMPRESAS. 2013. Disponível em: <http://www.sebrae.com.br〉. Acesso em 23 de maio de 2017.

SHANK, J. K.; GOVINDARAJAN, V. A revolução dos custos: como reinventar e redefinir sua estratégia de custos para vencer em mercados crescentemente competitivos. 2. ed. Rio de Janeiro: Campus, 1997.

VAN STEL, A.; CARREE, M.; THURIK, R. The effect of entrepreneurial activity on national economic growth. Small Business Economics, v. 24, n. 3, p. 311-321, 2005.

VOGEL, J.; WOOD JR, T. Práticas gerenciais de pequenas empresas industriais do Estado de São Paulo: um estudo exploratório. Revista ReGePe, v. 1, n. 2, p. 117-140, 2013.

WERNKE, R.; FRANCISCO, D. M.; JUNGES, I. Effect of deadlines in results of sales of rice growers' cooperatives: a case study. Custos e Agronegócios on line, v. 12, n. 4, p. 110-139, 2016. 